Review Article

\title{
Meat-Borne Parasites a Health Hazard Concern in the Sudan: A Review
}

\author{
Ghada Hassan Abdelnabi ${ }^{1, ~ *, ~ S h a w g i ~ M o h a m e d ~ H a s s a n ~}{ }^{1}$, Atif Elamin Abdelgadir², \\ Elgailani Ali Elamin ${ }^{1}$ \\ ${ }^{1}$ Department of Parasitology, Faculty of Veterinary Medicine, University of Khartoum, Khartoum North, Sudan \\ ${ }^{2}$ Veterinary Preventive Medicine and Public Health, Faculty of Veterinary Medicine, University of Khartoum, Khartoum North, Sudan
}

Email address:

ghadabdelnabi@hotmail.com (G. H. Abdelnabi), shawgimhassan64@hotmail.com (S. M. Hassan), atifvet@yahoo.com (A. E. Abdelgadir), elaminelgailani@yahoo.com (E. A. Elamin)

${ }^{*}$ Corresponding author

\section{To cite this article:}

Ghada Hassan Abdelnabi, Shawgi Mohamed Hassan, Atif Elamin Abdelgadir, Elgailani Ali Elamin. Meat-borne Parasites a Health Hazard Concern in the Sudan: A Review. Animal and Veterinary Sciences. Vol. 4, No. 6, 2016, pp. 103-107. doi: 10.11648/j.avs.20160406.14

Received: December 1, 2016; Accepted: December 19, 2016; Published: January 21, 2017

\begin{abstract}
Food-borne diseases in general have received more attention in the last decade, but little attention has been paid to parasitic food-borne infections. This is probably due to the fact that they are not associated with acute illness as bacterial and viral infections do. In the Sudan, the most important parasitic meat-borne infections are Taenia saginata, Toxoplasma gondii, Sarcocystis spp., Linguatula serrata and fish infection with trematode metacercaria. Control measures used in the country to prevent infection with these parasites are through inspecting meat in slaughterhouses for cysticercosis. Toxoplasma and Sarcocystsis infections are not considered during routine meat inspection due to lack of techniques for detection of these infections. Prevalence of infection with these parasites in humans and livestock in all States of Sudan is not available. Methods for routine diagnosis, monitoring or recording of these infections are inadequate, or not existing, in most of the laboratories. Studies are required to establish seroprevalence in livestock and humans. There is an urgent need to monitor and control meat-borne parasites using new technologies such as serological and molecular techniques, health education and vaccination. Researchers are urged to participate and establish innovative ways and means to control these diseases.
\end{abstract}

Keywords: Meat-Borne, Parasites, Zoonosis, Sudan

\section{Introduction}

Sudan is rich in animal resources approximately 106 million animal units [1] such as cattle, sheep, goats, camels, horses, donkeys and poultry, with consider potentials in animal production. The most important animal products are milk, meat, poultry meat, hides and to some extent hair and wool and animal traction power. Livestock production in the Sudan plays a pivotal role in national food security and generating hard currency income from export. Food safety has become a subject of policy importance internationally [2]. Experts of the Institute of Food Technologists, US, warn that parasites are a food safety concern that is generally underrecognized but is probably on increase due to globalization of the food supply [3]. Animals can be infected with parasitic and microbial pathogens. Some of these pathogens can be transmitted to humans via consumption of infected meat and milk causing food-borne diseases. Meat-borne parasites are transmitted to humans by ingestion of infected raw, undercooked or seasoned meat and meat-derived products of animal origin. The most important meat-borne parasites are helminths such as Trichinella spp., Taenia solium and Taenia saginata or protozoa viz, Toxoplasma gondii and Sarcocystis spp. or arthropods such as Linguatula serrata. Fish meat can be infected with various parasites viz, Diphyllobothrium spp., Spirometra spp., Opisthorchis spp., Clonorchis sinensis, Gnathostoma spp. and Anisakis spp. In the Sudan, the major meat-borne parasites are T. saginata, T. gondii, Sarcocystis spp., L. serrata and fish infection with trematode metacercaria.. 


\section{Materials}

Data were collected from different sources including journals, books and annual reports of Ministry of Animal Resources, Sudan. In addition, scientific publications by the help of internet websites up to the end of the year 2016 were reviewed.

Taenia saginata is a cosmopolitan parasite. This beef tape-worm is found in industrialized countries as well as in developing countries. Taeniasis is more common in populations that consume raw or undercooked beef infected with Cysticercus bovis the larval stage of the tape worm. Human taeniasis may be associated with abdominal discomfort, nausea, weight loss and anal pruritis, but occasionally more severe symptoms, such as intestinal perforation and peritonitis have been recorded [4]. In a community based study conducted among randomly selected 300 children, aged less than five years, in Khartoum. T. saginata was detected in $1.7 \%$ of the examined stool specimens [5]. About one thousand and five hundred food-handlers in Khartoum city, were screened for intestinal helminths, $0.3 \%$ were harboured $T$. saginata [6].

Bovine cysticercosis can inflict serious economic losses to cattle industry due to total or partial condemnation, refrigeration and downgrading of infected carcasses [7, 8]. The overall prevalence of $C$. bovis in cattle slaughtered in Khartoum State, Sudan was $0.42 \%$ [9]. However, comparing this with other countries it was found that in Egypt ranging between $0.23 \%$ to $20 \%[10,11,12]$, in Nigeria $26 \%$ [13], and in Zambia 6.1\% [14]. Darien [15] conducted a retrospective study to determine the prevalence of $C$. bovis in cattle slaughtered in Ghanawa abattoir in Khartoum State during 2005-2007. She reported that cysticercosis in the liver ranged from 0.29 to $0.58 \%$, in the heart $0.007-0.01 \%$, and in the masseter muscles $0.002-0.006 \%$ (Table 1 ).

Table 1. Infection rate of Cysticercus bovis in different organs of the slaughtered cattle during 2005-2007 in Khartoum State, Sudan.

\begin{tabular}{llllll}
\hline \multirow{2}{*}{ Year } & No examined cattle & No infected $(\%)$ & Organ & & \\
\cline { 4 - 6 } & & & Liver No infected $(\%)$ & Heart No infected (\%) & Masseter muscles No infected (\%) \\
\hline 2005 & 68232 & $303(0.44)$ & $293(0.43)$ & $7(0.01)$ & $3(0.004)$ \\
2006 & 80072 & $472(0.59)$ & $464(0.58)$ & $6(0.007)$ & $2(0.002)$ \\
2007 & 85871 & $264(0.31)$ & $249(0.29)$ & $9(0.01)$ & $6(0.006)$ \\
\hline
\end{tabular}

It seems that the liver is the most affected organ by $C$. bovis. This is quite significant as Sudanese have the habit of eating Marrara (raw liver, lung and rumen of ruminants). These figures are underestimated because routine visual meat inspection is the only method used for detection of $C$. bovis. Many studies indicated the underestimation of meat inspection, resulting in low prevalence of bovine cysticercosis by a factor of 3-10 times [16, 17]. More sensitive, rapid methods are needed to detect infection with cysticercosis in slaughterhouses or even in live animals.

Recently, for the first time in the Sudan parasite was detected in fish meat [18]. Fish borne trematode metacercaria was found in 6/50 (12\%) examined Mullet fish in the Red Sea Waters, Sudan [18]. No parasite cysts or eggs were found in the 30 stool samples taken from fishermen [18].

The causative agent of toxoplasmosisis is an intra-cellular protozoan, $T$. gondii, which is widely prevalent throughout the world in humans and warm-blooded animals. The cat is the only definitive host. This zoonotic disease is transmitted to humans by accidental ingestion of sporulated oocysts shed in feline feces, or by eating raw or semi-raw meat contaminated with tissue cysts. Most of human infections are asymptomatic and do not cause any disease. However, in pregnant women, toxoplasmosis is considered as a serious health problem and can lead to infection; of the foetus or newborn. Information on the prevalence in humans and animals in the Sudan and the risk of infection associated with food source is limited. Human toxoplasmosis was first studied by Carter and Fleck [19], using the Dye Test (DT), who reported a prevalence of $61 \%$ in four different States of the country. A sero-epidemiological survey of toxoplasmosis in pregnant Sudanese women showed that $34.1 \%(166 / 487)$ were seropositive for anti-toxoplasma $\mathrm{IgG}$ antibodies [20]. Eating raw meat was the risk factor for toxoplasmosis in pregnant Sudanese women [20]. Khalil et al., [21] reported overall prevalence $43.6 \%$ using Latex Agglutination Test (LAT) in Khartoum State. High prevalence rate was found among $75 \%$ HIV patients, $58.3 \%$ aborters, and $55.5 \%$ suspected cases. Khalil et al., [21] found the risk factors for $T$. gondii infection in humans were contact with cats, eating raw meat, and eating soil $(\mathrm{P}=0.0001,0.0001$ and 0.006, respectively). In Gezeira State, Abdel Hameed [22] found infection rate of $41.17 \%$ using LAT. In North Gezeira, $73.1 \%$ of childbearing age women showed seroactivity for $T$. gondii $\operatorname{IgM}$ and $\operatorname{IgG}$ [23]. Recently, toxoplasmosis was reported among pregnant women in Tendalty Town, White Nile State [24]. The overall prevalence of the parasite was $38.5 \%$ (40) of 104 examined serum samples [24].

Several studies were done on seroprevalence of $T$. gondii in camels in different localities in the Sudan. Zain Eldin et al., [25] reported an infection of 54\% using Indirect Hemagglution Test (IHT), Bornstein and Musa [26] 22.5\% via Sabin-Feldman Test and Abbas et al., [27] 12\% by (IHT). Afterwards, Elamin et al., [28] in Butana Plain using (LAT) reported $67 \%$, Manal et al., [29] found an overall prevalence of $61.7 \%$ in six different localities of the country (El Gedarif, North Kordofan, El Shawak, River Nile, Butana and El Hamra), and Khalil et al., [30] in three ecologically different areas recorded a prevalence of $22.2 \%$ utilizing LAT. The prevalence of $T$. gondii in camels in neighboring countries, in Egypt 27.9\% [31] and in Saudi Arabia 16\% [32].

However, limited publications are available on $T$. gondii infection in goats, sheep and cattle in the Sudan. The first 
study was conducted in 1985 [25], who reported an infection rate of $63 \%$ in goats, $34 \%$ in sheep, and $40 \%$ in cattle. Khalil and Intisar [33] found $57.5 \%$ and $32 \%$ of sheep and cattle in Khartoum State were seropositive to $T$. gondii antibodies, respectively. Recently, Elfahal et al., [34] using ELISA found the prevalence rate of antibodies in cattle was $12.7 \%$ and $14.9 \%$ in Khartoum and Gezira States, respectively. The prevalence rate of toxoplasmosis in other African and Arab countries in cattle in Ethiopia was 6.6\% [35], Egypt ranges from 21\% to $49 \%[36,37]$ and in Saudi Arabia 2\% [38]. In sheep and goats the infection rate was in Ethiopia $22.9 \%$ and $11.6 \%$, [35], in Ghana 33.2\% and 26.8\% [39] and in Saudi Arabia 39\% in sheep and $28 \%$ in goats, respectively [40].

Chicken toxoplasmosis was recorded for the first time in the Sudan this year 2016 [41]. A study was conducted in 3 states of the Sudan (Khartoum, River Nile and Sennar) in cages and free range chickens. Seroprevalence for $T$. gondii antibodies was 68/68 (100\%) examined samples [41].

Seroprevalence studies are required to be carried out in the Sudan in animals and humans. This data is useful in monitoring and reporting the disease. Advanced methods are needed to detect different infective stages of $T$. gondii in food and meat and to detect viable cyst in edible tissue.

Sarcocystis species are obligatory intracellular protozoan parasite, with a heteroxenous life cycle based on prey (intermediate) - predator (definitive) host relationship. Humans are the definitive hosts for two species, Sarcocystis hominis and Sarcocystis suihominis but cysts of several unidentified species occasionally are found in human muscle [42]. Eating raw or undercooked beef and pork containing mature sarcocysts of $S$. hominis and $S$. suihominis, respectively, has resulted in human acquiring intestinal sarcocystosis [43]. In Sudan, several studies have been conducted to determine prevalence of Sarcocystis spp. in food animals [44, 45]. These studies have not attempted to differentiate species of Sarcocystis found in meat.

Linguatuliasis is a zoonotic disease. The disease has been reported in the Middle East, Africa, America, and South-East Asia [46, 47, 48, and 49]. The causative agent of the disease is Linguatula serrata (Tongue worm) a pentasomide parasite. Adult of $L$. serrata inhabit the nasal sinuses and nasopharynx of carnivores mammals, especially dogs. Intermediate host are various mammalian species but herbivores are the best hosts for the development of nymphal stage. The intermediate hosts become infected by ingestion of eggs, which containing fully developed larvae, that are discharged in the dogs' nasal secretion, and which develop to nymphal stage in various organs particularly in Mesenteric Lymph Nodes (MLNs). There are two types of linguatuliasis in human: nasopharyngal and visceral. Linguatuliasis has been reported in the Sudan and known as "Marrara syndrome" and occur due to consumption of Marrara (raw liver, lungs, trachea and rumen of goats and sheep infected with larvae $L$. serrate [47, 48]. $L$. serrata nymph was isolated from human and goat in the Sudan $[47,48,50]$. A survey in an endemic village of $L$. serrata infection in the Sudan, showed that 20\% (48/240) individuals experienced symptoms of allergic nasopharyngitis [48].
Clinical signs include itching in the throat and nose, unilateral conductive deafness, tinnitus and facial palsy. Moreover, adults L. serrata were found in the nasal passages of 56 and $47 \%$ of male and female dogs in the endemic area [48].

\section{Conclusion}

It is evident from the research conducted in meat inspection and laboratory examination that meat-borne parasites constitute health hazards. The parasites detected in the meat may be much underestimated as there is no data available in rural areas of the country among resource-poor people. It is expected that these parasites are widespread among these people threatening their lives and lowering their productivity. To provide parasite free meat, it is necessary to direct research towards efficient detection of these parasites in live and slaughtered animals. Advanced techniques for detection of parasites in the meat are required in the Sudan.

\section{References}

[1] Anon 2014. Ministry of Animal Resources Sudan, Information Center.

[2] Hanak E, Boutrit E, Fabre P, Pineiro M. Food safety management in developing countries. Proceedings of an international workshop, CIRAD - FAO, 11-13 December 2000; Montpellier, France.

[3] Dorny P, Praet N, Deckers S, Gabriei S. Emerging food- borne parasites, Vet. Parasitol. 2009; 163: 196-206.

[4] Jongwutiwes S, Putaporntip C, Chantachum N, P Sampatanukul. Jejunal perforation caused by morphological abnormal Taenia saginata infection. J. Infect. 2004; 49: 324-328.

[5] Karrar ZA, Rahim FA. Prevalence and risk factors of parasitic infections among under-five Sudanese children: a community based study. East. Afr. Med. J. 1995; 72: 103-109.

[6] Babiker MS, Ali M, Ahmed ES. Frequency of intestinal parasites among food-handlers in Khartoum. Sudan. Eastern Mediterranean Health J. 2009; 15 (5): 1098-1099.

[7] Yoder DR, Ebel ED, Hancock DD, Combs BA. Epidemiologic findings from an outbreak of cysticercosis in feedlot cattle. J. Am. Vet. Med. Assoc. 1994; 205: 45-50.

[8] Giesecke WH. 1997. Prevalence and economic implications of taeniasis/ cysticercosis in South Africa. In: Cysticercosis report on a workshop held at Onderstepoort Veterinary Institute, Onderstepoort, South Africa, 18-19 August 1997. pp. 19-70.

[9] Anon 2011. Ministry of Animal Resources and Fisheries, Sudan Annual Report (2011).

[10] Haridy FM, Ibrahim BB, Morsy TA, Ramadan NI. Human taeniasis and cysticercosis in slaughtered cattle, buffaloes and pigs in Egypt. J. Egypt. Soc., Parasitol. 1999; 29 (2): 375-394.

[11] Abdo BRN, Sayed ASM, Hussein AAA, Arafa MI. Occurrence of cysticercosis in cattle and buffaloes and Taenia saginata in man in Assiut Governance of Egypt. Vet. Word. 2009; 2: 173-176. 
[12] Abdel-Hafeez EA, Kamal AM, Abdel Gelil NH, Abdel-Fatah MM. Parasites transmitted to human by ingestion of different types of meat, El-Minia City, El-Minia Governorate, Egypt. J. Egypt. Soc., Parasitol. 2015; 45 (3): 671-680.

[13] Opara MN, Ukpong UM, Okoli IC, Anosike JC. Cysticercosis of slaughter cattle in southeastern Nigeria. Ann. N. Y. Acad. Sci. 006; 1081: 339-346.

[14] Dorny P, Phiri I, Gabriel S, Speybroeck N, Vercruysse J. A sero-epidemiological study of bovine cysticercosis in Zambia. Vet. Parasitol. 2002; 104 (3): 211-215.

[15] Darien KM. Ante-mortem and post-mortem causes of condemnation of meat in Ghanawa Slaughterhouse in Khartoum State. 2008; MTAH thesis, University of Khartoum, Sudan.

[16] Geerts S, Kumar V, Aerts N, Ceulemans F. Comparative evaluation of immunoelectrophoresis, counterimmunoelectrophoresis and ELISA for the diagnosis of Taenia saginata cysticercosis. Vet. Parasitol. 1981; 88: 43-49.

[17] Dorny P, Vercammen F, Brandt J, Vansteenkiste W, Berkvens D. Sero-epidemiological study of Taenia saginata cysticercosis in Belgian cattle. Vet. Parasitol. 2000; 8: 299-307.

[18] Gumaa N, AbdulRaheem EM, Nur-Eldaiem Z, Hussein M, Nasri M, Abdelhaleem A. New record of trematode metacercaria as zoonotic parasite in Mullet fish in the Sudanese Red Sea Waters. J. Biomed. Pharmaceut. Res. 2015; 4 (3): 66-69.

[19] Carter F, Fleck D. The incidence of Toxoplasma antibodies in the Sudanese. Transaction of the Royal. Soc. of Trop. Med. and Hyg. 1966; 60: 539-543.

[20] Elnahas A, Gerais AS, Elbashir MI, Eldien ES, Adam I. Toxoplasmosis in pregnant Sudanese women. Saudi. Med. J. 2003; 28(8): 868-70.

[21] Khalil M, Ahmed AA, Intisar E. Prevalence and risk factors for Toxoplasma gondii infection in humans from Khartoum State. Int. J. Public. Health. Epidemiol. 2013; 2 (3): 60-66.

[22] Abdel-Hameed AA. Sero-epidemiology of toxoplasmosis in Gezira, Sudan, J. of Trop. Med. Hyg. 1991; 94 (5): 329-332.

[23] Khalil M, Peter K, Alia B, Marek M, El Taib G, Ali A, Intisar E. Immuno-diagnosis of latent toxoplasmosis in childbearing age women in rural areas in El Geizera State Sudan. Inter. Med. Sci. 2009; 1 (7): 272-277.

[24] Tamomh AG, Mohamed HY, Magboul AM, Hassan IM, Ibrahim RM, Mohammed HMA, Dafaallah TYI. Prevalence of toxoplasmosis among pregnant gynecological women in Tendalty Hospital, Tendalty Town, White Nile State, Sudan. World. J. Biol. Med. Sci. 2016; 3 (3): 76-83.

[25] Zain Eldin EA, Elkhawad SE, Kheir HSM. A serological survey for Toxoplasma antibodies in cattle, sheep, goats and camels (Camelus dromedarius) in the Sudan. Revue d'ÉLevage et de Médecine Vétérinaire des Pays Tropicaux. 1985; 38: 257 249.

[26] Bornstein S, Musa BE. Prevalence of antibodies to some viral pathogens, Brucella abortus and Toxoplasma gondii in serum from camels (Camelus dromedarius) in Sudan. J. Vet. Med. 1987; 34 (5): 364-370.

[27] Abbas B, El Zubair E, Yassin T. Survey for certain zoonotic diseases in camels in Sudan. Rev. E'lev. Med. Vet. Pays. Trop. 1987; 40: 31-33.

[28] Elamin E A, Elias S, Daugschies A, Rommel M. Prevalence of Toxoplasma gondii antibodies in pastoral camels (Camelus dromedarius) in the Butana plains, mid-Eastern Sudan. Vet. Parasitol. 1992; 43 (3-4): 171-175.

[29] Manal YI, Majid AM, Magzoub E. Seroprevalence of Toxoplasma gondii antibodies in camels (Camelus dromedarius) in Sudan. Al Buhuth, The Sudan J. of Scientific Research. 2005; 9 (1): 94-102.

[30] Khalil M, Gadir AEA, Rahman MMA, Yassir OM, Ahmed AA, Intisar E. Prevalence of Toxoplasma gondii antibodies in camels and their herds in three ecologically different areas in Sudan. J. Caml. Pract. and Research. 2007; 14 (1): 11-13.

[31] Michael S, El Refai A, Morsy T. The incidence of Toxoplasma antibodies among camels in Egypt. J. Egypt. Soc. Parasit. 1977; 7: $129-132$

[32] Hussein MF, Bakkar N, Basmacil SM, Gar El Nabi AR. Prevalence of toxoplasmosis in Saudi Arabian camels (Camelus dromedarius). Vet. Parasitol. 1988; 28: 175-178.

[33] Khalil MK, Intisar E. Seroprevalence of Toxoplasma gondii antibodies in farm animals (camels, cattle, and sheep) in Sudan. J. Vet. Med. and Anim. Heal. 2011; 3: 36-39.

[34] Elfahal AM, Elhassan AM, Hussien MO, Enan KA, Musa AB, El Hussein AM. Seroprevalence of Toxoplasma gondii in dairy cattle with reproductive problems in Sudan. ISRN Veterinary Science. 2013; vol. 2013, Article ID 895165, 4 pages, 2013. doi:10.1155/2013/895165.

[35] Bekele T, Kasali OB. Toxoplasmosis in sheep, goats and cattle in central Ethiopia. Veterinary Research Communication. 1989; $13: 371-375$.

[36] El Ridi AM, Nada SM, Aly AS, Habeeb SM, Aboul Fattah MM Serological studies on toxoplasmosis in Zagazig Slaughterhouse. J. Egypt. Soc. Parasitol. 1990; 20: 677-687.

[37] Ibrahim BB, Salama MM, Gawish NI, Haridy FM. Serological and histopathological studies on Toxoplasma gondii among the workers and the slaughtered animals in Tanta Abattoir. J. Egypt. Soc. Parasitol. 1997; 27: 273-278.

[38] El Metenawy TM. Seroprevalence of Toxoplasma gondii antibodies among domesticated ruminants at Al Qassim Region, Saudi Arabia. Dtsch. Tierarztl. Wochenschr. 2000; 107: 32-33.

[39] Vanderpuije WNA, Bosompem KM, Canacoo EA, Wastling JM, Akanmori BD. The prevalence of anti-Toxoplasma gondii antibodies in Ghanaian sheep and goats. Acta. Tropica. 2000; 76: $21-26$.

[40] Amin M, Morsy A. Anti-Toxoplasma antibodies in butchers and slaughtered sheep and goats in Jeddah Municipal Abattoir, Saudi Arabia. J. Egypt. Soc. Parasitol. 1997; 27: 913-918.

[41] Hussien MO, Alfaki SH, El Hussein ARM. Seroprevalence of Toxoplasma gondii in.chickens (Gallus domesticus) in Sudan. Int. J. Infect. 2016 (In press); doi: 10.17795/iji-40312.

[42] Pathmanathan R, Khan SP. Three cases of human Sarcocystis infection with a review of human muscular sarcocystosis in Malaysia. Trop. Geogr. Med. 1992; 44: 102-108.

[43] Fayer R. Sarcocystis spp. in human infections. Clin. Microbiol. Rev. 2004; 17: 894-902. 
[44] Ginawi MA, Shommein A. M. Prevalence of sarcosporidiosis in sheep, goats and camels in the Sudan. Sudan. J. Vet. Sci. \& Anim. Hus. 1977; 18: 92-97.

[45] Hussein SH, Warrag M. Prevalence of Sarcocystis in food animals in the Sudan. Trop. Anim. Health. Prod. 1985; 17: 100-101.

[46] Gardiner CH, Dyke JW, Shirely SF. Hepatic granuloma due to a nymph of Linguatula serrata in a woman from Michigan a case report and review of the literature. Am. J. Trop. Med. Hyg. 1984; 33: 187-189.

[47] El Hassan AM, Eltoum IA, El Asha BMA. The Marara syndrome isolation of Linguatula serrata nymph from a patient and the viscera of goats. Trans. R. Soc. Trop. Med. Hyg. 1991; 85: 309 .
[48] Yagi H, El Bahari S, Mohamed HA, Ahmed el-R S, Mustafa B, Mahmoud M, Saad MBA, Sulaiman SM, el Hassan AM. The Marrara syndrome: a hypersensitivity reaction of the upper respiratory tract and buccopharyngeal mucosa to nymphs of Linguatula serrata. Acta. Trop. 1996; 62: 127-134.

[49] Acha, PN, Szyfres B. Pentastomosis. In: Acha, P. N. and Szyfres B. (Eds) Zoonosis and communicable diseases common to man and animals (parasitosis). Third edition, Washington, D. C., Scientific and technical publication. 2003; pp. 345-380.

[50] Elbadawi el KS, el-Gezuli AY, Eisa A M, Slepnev NK, Linguatula serrata nymph in a goat in the Sudan. Veterinary Record. 1978; 102:171. 